\title{
Applications of Silver Nanowires on Transparent Conducting Film and Electrode of Electrochemical Capacitor
}

\author{
Yuan-Jun Song, ${ }^{1,2}$ Jing Chen, ${ }^{3}$ Jing-Yuan Wu, ${ }^{1,2}$ and Tong Zhang ${ }^{1,2}$ \\ ${ }^{1}$ School of Electronic Science and Engineering, Southeast University, Nanjing 210096, China \\ ${ }^{2}$ Suzhou Key Laboratory of Metal Nano-Optoelectronic Technology, Suzhou Research Institute of Southeast University, \\ Suzhou 215123, China \\ ${ }^{3}$ School of Physics and Key Laboratory of Weak-Light Nonlinear Photonics, Nankai University, Tianjin 300071, China \\ Correspondence should be addressed to Tong Zhang; tzhang@seu.edu.cn
}

Received 28 February 2014; Revised 15 May 2014; Accepted 19 May 2014; Published 2 June 2014

Academic Editor: Qin Chen

Copyright (C) 2014 Yuan-Jun Song et al. This is an open access article distributed under the Creative Commons Attribution License, which permits unrestricted use, distribution, and reproduction in any medium, provided the original work is properly cited.

Silver nanowire has potential applications on transparent conducting film and electrode of electrochemical capacitor due to its excellent conductivity. Transparent conducting film (G-film) was prepared by coating silver nanowires on glass substrate using Meyer rod method, which exhibited better performance than carbon nanotube and graphene. The conductivity of G-film can be improved by increasing sintering temperature. Electrode of electrochemical capacitor (I-film) was fabricated through the same method with G-film on indium tin oxide (ITO). CV curves of I-film under different scanning rates had obvious redox peaks, which indicated that I-film exhibited excellent electrochemical pseudocapacitance performance and good reversibility during charge/discharge process. In addition, the specific capacitance of I-film was measured by galvanostatic charge/discharge experiments, indicating that I-film exhibits high special capacitance and excellent electrochemical stability.

\section{Introduction}

In recent years, noble metal nanomaterials, especially silver nanomaterial become the focus of research because of their unique physical and chemical properties, which has been widely used in catalysis [1], optical, electrical $[2,3]$, and antibacterial [4] areas. Among these various silver nanostructures, nanowire has attracted intense forces due to its high dc conductivity and optical transmittance. As optoelectronic devices become smaller and lighter, there is an increasing need for efficient transparent electrodes. The most common material of transparent electrodes is indium tin oxide (ITO); however, ITO cannot keep pace with the development of optoelectronic devices because of its high cost, brittleness, and critical preparation process. Although people have tried to use other materials to fabricate transparent electrodes, such as carbon nanotubes (CNTs) [5-8], graphene [9-11], and conducting polymer [12-14], the problem that how to achieve ratio of transmittance to sheet resistance (Rs) as high as ITO still cannot be solved. Therefore, many groups put efforts on metallic nanowires, particularly silver nanowires. Leem et al. [15] have pioneered silver nanowires as the electrode in solar cells, and the transmittance of it was $89.3 \%$ with low Rs of $10 \Omega$ /sq. Since then, silver nanowire films have been fabricated by rod-coating technique [16] and spay-coating method [17]. Therefore, silver nanowire can be used as a replacement of ITO in the future. In order to further decrease the Rs of silver nanowire film, Bergin et al. [18] studied the effects of the length and diameter of silver nanowires on their properties. Longer nanowires can result in lower Rs due to fewer connections between nanowires. Therefore, the preparation of ultralong nanowires is an urgent issue. Apart from increasing the length of nanowire to improve its properties, $\mathrm{Hu}$ et al. applied mechanical pressing method to reduce the resistance of junctions, which can make connection of silver nanowires closer leading to the increase of the conductivity [19]. They also found that coating gold on the film is an efficient way, which can make the surface of silver nanowire smooth leading to the decrease of the junction resistance. Zhu et al. [20] used plasma treatment to remove the polymer coated on the surface of silver nanowire and welded the junctions, improving the performance of silver nanowire 
film. However, the large contact resistance of internanowires is still a limitation of the development of silver nanowire films in optoelectronic and electronic devices.

In addition, silver nanowire can also be used as electrodes of electrochemical capacitor. Transparent capacitors have potential application on energy storage [21-23]. Sorel et al. [24] prepared transparent capacitor by spray-coating silver nanowires on polymer films, which exhibited capacitor properties with $1.1 \mathrm{uF} / \mathrm{cm}^{2}$. However, compared with other electrodes of capacitor, the specific capacitance was much lower. Pan et al. [25] found that nanostructured AgO electrode showed excellent electrochemical properties, and silver nanowires can be oxidized to $\mathrm{Ag}_{2} \mathrm{O}$ forming $\mathrm{Ag} / \mathrm{Ag}_{2} \mathrm{O}$ core-shell nanostructures during the electrochemical process [26]; therefore, silver nanowire is a promising candidate of electrochemical capacitor.

In this paper, we prepared long silver nanowires by a simple method reported in our previous work. Based on this, transparent conducting film (G-film) and electrode of electrochemical capacitor (I-film) were fabricated by coating silver nanowires on glass or ITO, respectively, and their characteristics were investigated. The relationship between transmittance and Rs of G-film was discussed. The conductivity of G-film was improved by increasing sintering temperature. By cyclic voltammetry and galvanostatic charge/discharge experiments, the capacitor properties of I-film were studied, indicating that silver nanowire has high and stable electrochemical capacitance which can be used as material of electrode of electrochemical pseudocapacitance.

\section{Experimental}

Silver nitrate $\left(\mathrm{AgNO}_{3} 99+\%\right)$, sodium chloride $(\mathrm{NaCl})$, ethylene glycol (EG), concentrated sulfuric acid $\left(\mathrm{H}_{2} \mathrm{SO}_{4}\right)$, and hydrogen peroxide $\left(\mathrm{H}_{2} \mathrm{O}_{2}\right)$ were all purchased from Nanjing Chemical Reagent Co., Ltd. Polyvinyl pyrrolidone (PVP, K88) was purchased from Aladdin. Indium tin oxide (ITO) was purchased from Nanjing Chemical Reagent Co., Ltd.

The morphologies and Energy Dispersive Spectrometer (EDS) of silver nanowires were measured by scanning electron microscope (SEM) (SIRION, USA). The Rs of silver nanowire film was measured by four-probe technique with a Keithley 2701 source meter. UV-vis spectra were recorded by a fiber-optic spectrometer (PG2000, Ideaoptics Technology Ltd., Shanghai, China). Electrochemical capacitance property of silver nanowire electrode is investigated through cyclic voltammetry $(\mathrm{CV})$ and galvanostatic charge/discharge measurements using an electrochemical workstation (CHI 760D, $\mathrm{CH}$ Instruments Co., Ltd.).

2.1. Preparation of Silver Nanowires. Silver nanowire was prepared by the method reported in our previous work [27]. In each synthesis, $1 \mathrm{~mL}$ EG solution of $\mathrm{AgNO}_{3}$ (0.9 M) and $0.6 \mathrm{~mL}$ EG solution of $\mathrm{NaCl}(0.01 \mathrm{M})$ were added into 18.4 $\mathrm{mL}$ EG solution of PVP $(0.286 \mathrm{M})$. Then the mixture was refluxed at $185^{\circ} \mathrm{C}$ for $20 \mathrm{~min}$. After the above processes, the excess PVP and EG were removed by adding deionized water centrifuging at $14000 \mathrm{rpm}$ for $10 \mathrm{~min}, 3$ times.

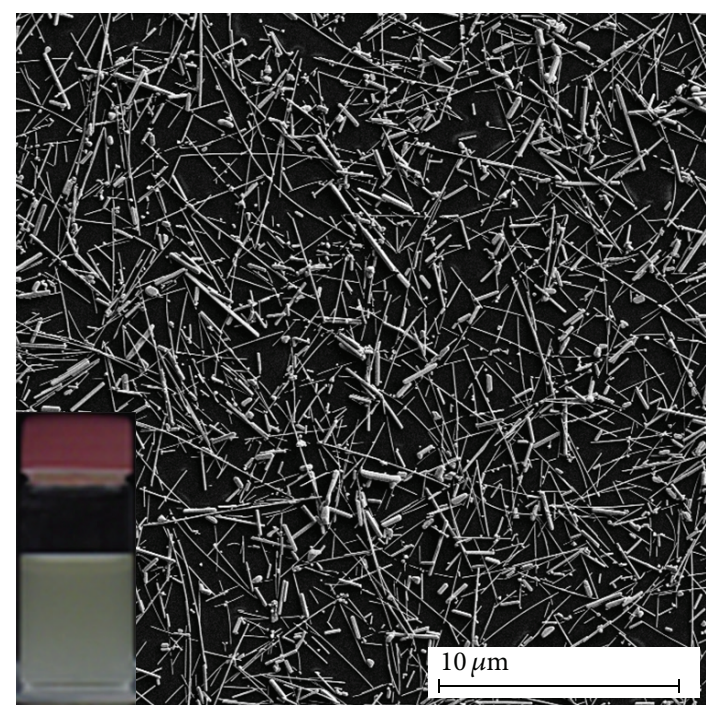

FIGURE 1: The SEM image of silver nanowires: the inset is the corresponding solution.

2.2. Procedure of Silver Films on Glass and ITO. The glass and ITO substrates were treated by the mixture solution of concentrated sulfuric acid and hydrogen peroxide under ultrasonication for $30 \mathrm{~min}$, which can make them hydrophilic. In this case, uniform film can be obtained. Silver nanowires were coated on glass or ITO substrate with treatment, using Meyer rod, and then heated in $150^{\circ} \mathrm{C}$ for $20 \mathrm{~min}$. The film obtained on glass substrate was named G-film. Samples 1 to 5 are G-films fabricated with $2 \mathrm{mM}, 1.75 \mathrm{mM}, 1.5 \mathrm{mM}, 1 \mathrm{mM}$, and $0.5 \mathrm{mM}$ silver nanowires solution, respectively. The film obtained on the ITO was named I-film. The two kinds of films have different properties because of different substrates.

\section{Results and Discussions}

3.1. Morphology of Silver Nanowire Film. As shown in Figure 1, uniform silver nanowire film was prepared using Meyer rod. The length of most silver nanowire exceeds $5 \mu \mathrm{um}$, which is long enough to be connected into a network. The inset in Figure 1 is silver nanowire colloids. The color of silver colloids is yellowish white, similar to the highly purified silver nanowire colloids obtained after cross-flow filtration [28]. Preparation of high yield and long silver nanowires has been studied by many groups; however, these reaction processes are usually complex or difficult to control $[29,30]$. Without fine control of reactant concentrations and growth process, the obtained silver nanowires are always in low yield accompanied by large amounts of by-products such as nanocubes or nanospheres growing from isotropic seeds, which influences the properties of silver nanowire films.

3.2. Transparent Conducting Film. Optical transmittance over a large wavelength range is an important property for transparent and conductive film. Figure 2 exhibits the transmittances of G-films with different thicknesses, which were fabricated on glass substrates with different concentrations of silver nanowires. The transmittance of sample 1 is $13 \%$, which 


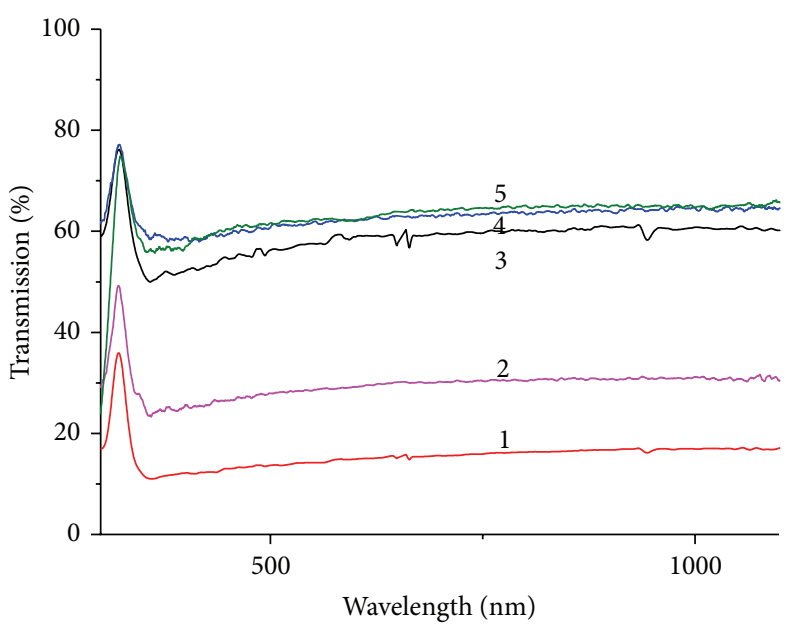

Sample 1: $T=13 \% R=10 \Omega / \mathrm{sq} \quad$ Sample $4: T=62 \% R=80 \Omega / \mathrm{sq}$ Sample 2: $T=38 \% R=15 \Omega / \mathrm{sq} \quad$ Sample $5: T=65 \% R=110 \Omega / \mathrm{sq}$ Sample 3: $T=58 \% R=50 \Omega / \mathrm{sq}$

FIGURE 2: The transmittance and Rs of G-film fabricated with different concentrations of silver nanowires. (1) $2 \mathrm{mM} / \mathrm{L}$; (2) $1.75 \mathrm{mM} / \mathrm{L}$; (3) $1.5 \mathrm{mM} / \mathrm{L}$; (4) $1 \mathrm{mM} / \mathrm{L}$; (5) $0.5 \mathrm{mM} / \mathrm{L}$.

is very low. When the concentration decreased from $2 \mathrm{mM}$ to $0.5 \mathrm{mM}$, the transmittance of samples showed an increasing tendency reaching $31 \%, 58 \%, 62 \%$, and $65 \%$, respectively. In addition, it can be seen in Figure 2 that the transmittances of G-films keep stable in the near-infrared regions, which is important for solar cells. However, the transmittance of ITO decreased from $1100 \mathrm{~nm}$ described to its plasmon resonance peak at $1300 \mathrm{~nm}$ [19]. The conductivity of G-films is also affected by the thickness of film. As shown in Figure 2, with the increase of thickness, the Rs of G-film drops.

As mentioned in the introduction, it is a big problem to decrease the junction resistance of silver nanowire film. We found that increasing the sintering temperature is a facile and effective way to improve the conductivity of silver nanowire film. As shown in Table 1, when the sintering temperature was $150^{\circ} \mathrm{C}$, the Rs of sample 4 was $80 \Omega /$ sq. Increasing sintering temperature to $200^{\circ} \mathrm{C}$, the Rs dropped to $45 \Omega /$ sq. Because the PVP coated on surface of silver nanowires was decomposed partially at $200^{\circ} \mathrm{C}$, the surfaces of silver nanowires can connect together leading to higher conductivity [31]. In addition, at $200^{\circ} \mathrm{C}$ some silver nanowires can be welded together. When the sintering temperature was $250^{\circ} \mathrm{C}$, PVP was almost removed and most of the junctions between silver nanowires were melted resulting in the lower Rs with $15 \Omega /$ sq, which can be seen in Figure 3(a). When the sintering temperature was $300^{\circ} \mathrm{C}$, although some of silver nanowires were broken, the film still was a conductive network with lower Rs $(6 \Omega / s q)$ shown in Figure 3(b). However, when thinner sample 5 was sintered at $300^{\circ} \mathrm{C}$, many silver nanowires were broken leading to nonconductive film which can be seen in Figure 3(d). At $400^{\circ} \mathrm{C}$, the silver nanowires of sample 4 were almost broken (in Figure 3(c)). According to (1) [20], we can calculate $\sigma_{\mathrm{dc}} / \sigma_{\mathrm{op}}$ which can evaluate the performance of transparent conducting film, the higher $\sigma_{\mathrm{dc}} / \sigma_{\mathrm{op}}$ means the higher ratio of transmittance to Rs. The $\sigma_{\mathrm{dc}} / \sigma_{\mathrm{op}}$ of sample 4 after treated at
TABLE 1: Rs of samples 4 and 5 under different sintering temperatures.

\begin{tabular}{lccccc}
\hline Sintering temperature $/\left({ }^{\circ} \mathrm{C}\right)$ & 150 & 200 & 250 & 300 & 400 \\
Rs of sample $4(\Omega / \mathrm{sq})$ & 80 & 45 & 15 & 6 & $/$ \\
\hline
\end{tabular}

$300^{\circ} \mathrm{C}$ was 116.5 which is higher than that of carbon nanotube $[32,33]$ and graphene [34]. Therefore, G-films have potential application on optoelectronic devices:

$$
T=\left(1+\frac{188.5}{\mathrm{Rs}} \frac{\sigma_{\mathrm{op}}}{\sigma_{\mathrm{dc}}}\right)^{-2} .
$$

3.3. Electrode of Electrochemical Capacitor. The cyclic voltammetry is used to evaluate the electrochemical properties of I-film. All these electrochemical measurements are conducted in 1.0 M KOH using a three-electrode system. Figure 4 showed CV curves of I-film electrode at a scan rate from 10 to $100 \mathrm{mV} \mathrm{s}^{-1}$. The $\mathrm{CV}$ curve of I-film exhibits definitely different capacitance properties from electric double layer capacitance which has rectangular CV curve. Distinct redox peak can be seen from Figure 4 in the applied potential from -0.5 to $0.5 \mathrm{~V}$ versus $\mathrm{Hg} / \mathrm{HgO}$ resulting from the redox reaction between $\mathrm{Ag}$ and $\mathrm{Ag}_{2} \mathrm{O}$ [35] described as (2). The capacitance of I-film at different scan rates can be estimated by the area of the closed circle. Changes in capacitance at different scan rates result from that at low scan rates; the diffusion of ions throughout the reaction system is unlimited leading to full use of silver nanowire as electrode, while at high scan rates, the capacitance performs double-layer or non-Faradic behavior so that silver is not fully oxidized or reduced resulting in the decrease of the capacitance [36]. Results indicate that I-film shows excellent electrochemical pseudocapacitance performance and good reversibility during charge/discharge process:

$$
2 \mathrm{Ag}+2 \mathrm{OH}^{-}=\mathrm{Ag}_{2} \mathrm{O}+\mathrm{H}_{2} \mathrm{O}+2 \mathrm{e}^{-} .
$$

Usually, silver experiences a reversed redox in an alkaline condition. In the first step, Ag is electrochemically oxidized to $\mathrm{Ag}_{2} \mathrm{O}$ by $\mathrm{OH}^{-}$, leaving a water molecule and two electrons. In a converse direction, a water molecule was separated into $\mathrm{H}^{+}$ and $\mathrm{OH}^{-}$, so that $\mathrm{Ag}_{2} \mathrm{O}$ can be reduced to $\mathrm{Ag}$ by $\mathrm{H}^{+}$leaving $\mathrm{OH}^{-}$. As a result, silver nanowires were transformed into $\mathrm{Ag} / \mathrm{Ag}_{2} \mathrm{O}$ core-shell nanostructures as Figure 5(a) showed. To detect the production of $\mathrm{Ag}_{2} \mathrm{O}$ during the process, the EDS with a large spot size (approximately $5 \mu \mathrm{m}$ ) was performed. In Figure 5(b), we can see the percentages of elements. EDS spectrum exhibited that the atom ratio between $\mathrm{Ag}$ and $\mathrm{O}$ is less than two. The reason is that sources of oxygen are from $\mathrm{Ag}_{2} \mathrm{O}$ and PVP which is covered on the surface of silver nanowires, and the core of silver nanowires is still Ag element. Thus, the experiment result is consistent with theory and demonstrates the form of $\mathrm{Ag}_{2} \mathrm{O} / \mathrm{Ag}$ core-shell nanostructures during the charge/discharge process.

There is a linear relationship between the scan rate and the response current according to (3) [37], where $I$ is the discharge current (mA); $C$ is the capacitance; $d V / d t$ is the 


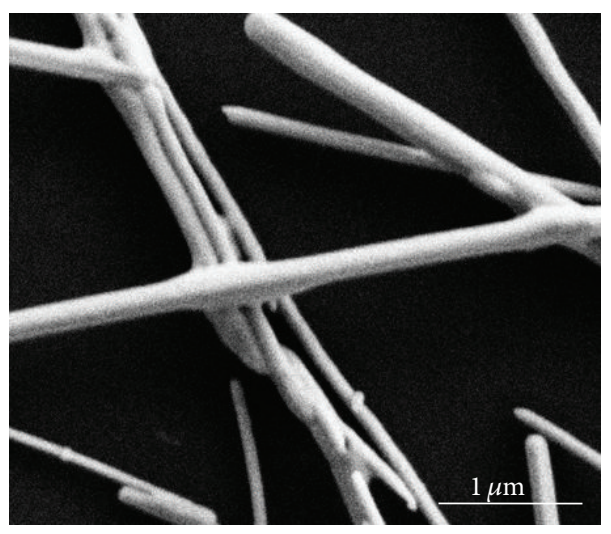

(a)

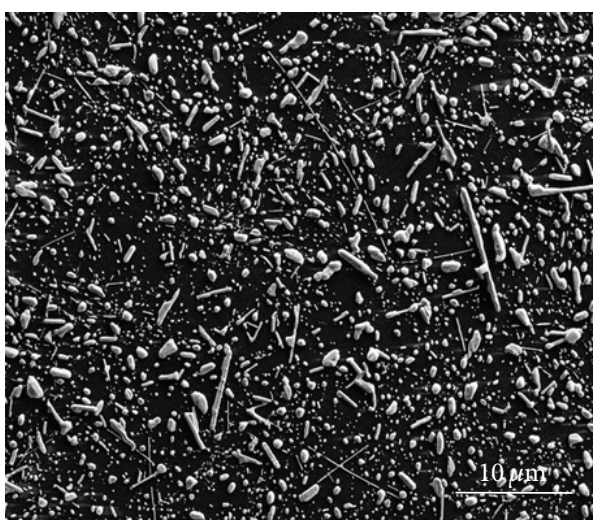

(c)

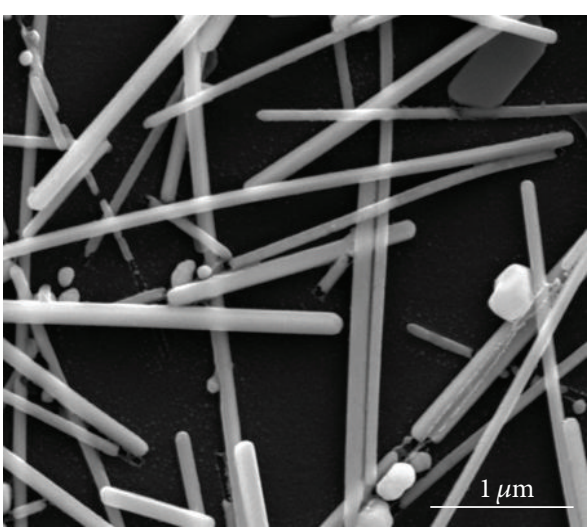

(b)

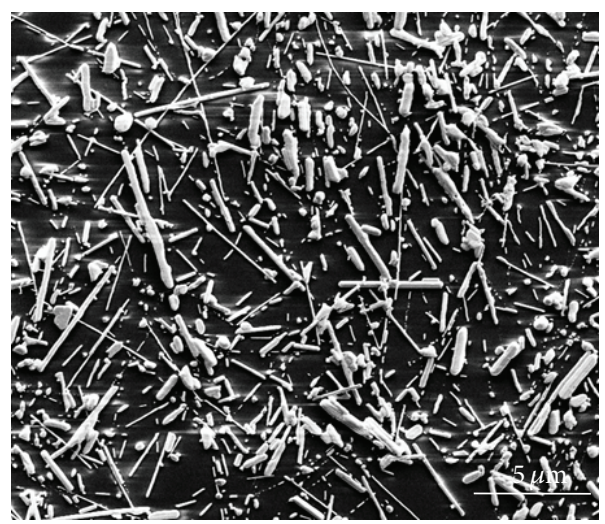

(d)

Figure 3: SEM images of G-film at different sintering temperature. (a) Sample 4 at $250^{\circ} \mathrm{C}$; (b) sample 4 at $300^{\circ} \mathrm{C}$; (c) sample 4 at $400^{\circ} \mathrm{C}$; (d) sample 5 at $250^{\circ} \mathrm{C}$.

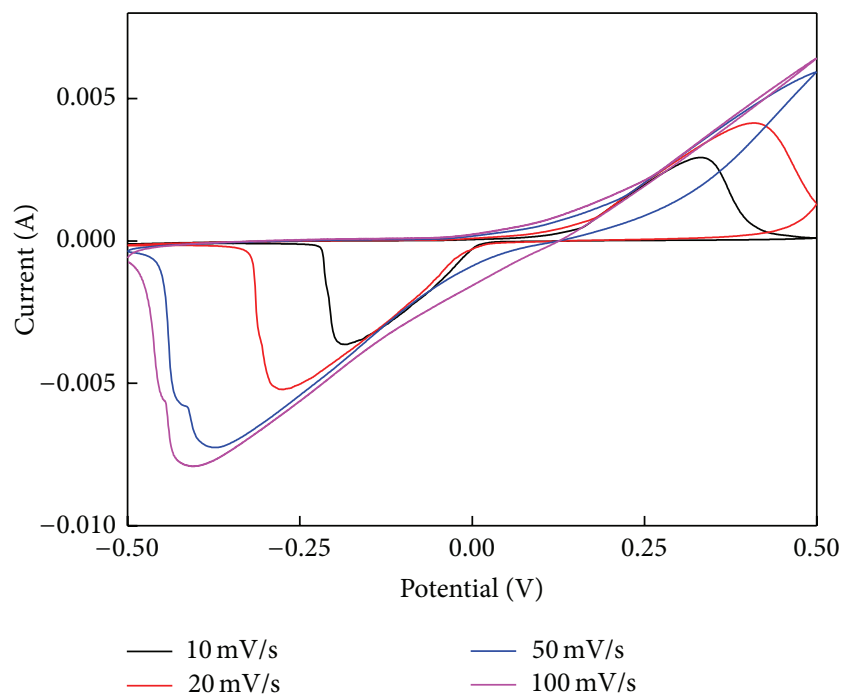

FIGURE 4: CV curves of I-film under different scanning rates.

scan rate of the cyclic voltammetry. The enclosed area of the cyclic voltammetry curve can be used to estimate the electrochemical capacitance. The specific capacitance $C_{s}$ is calculated using (4), where $s$ is the area of active material $\left(\mathrm{cm}^{2}\right)$ :

$$
\begin{aligned}
I & =C \times\left(\frac{d V}{d t}\right) \\
C_{s} & =\frac{C}{s}=\frac{I}{[(d V / d t) \times s]} .
\end{aligned}
$$

The galvanostatic charge/discharge experiments are conducted at a potential window from -0.5 to $0.5 \mathrm{~V}$ to study the specific capacitance of I-film. Figure 6 shows the galvanostatic charge/discharge curves of I-film at a current density from 0.5 to $6 \mathrm{~mA} \mathrm{~cm}^{-2}$. As Table 2 showed, the specific capacitance of I-film increased from 42.2 to $41.76 \mathrm{mF} / \mathrm{cm}^{2}$ when the current density increased from 0.5 to $3.0 \mathrm{~mA} / \mathrm{cm}^{2}$, which is only $1 \%$ decay. However, the specific capacitance of I-film sharply declined to $27 \mathrm{mF} / \mathrm{cm}^{2}$ under $6.0 \mathrm{~mA} / \mathrm{cm}^{2}$. The reason is that larger current density results in shorter time of redox between $\mathrm{Ag} / \mathrm{Ag}_{2} \mathrm{O}$, so that ions have not enough time to diffuse from electrolyte and interphase [26]. In addition, the surface of nanowires is covered by PVP, which also have effect on the charge/discharge rate [38]. Figure 7 presented that the capacitance retention of I-film at a current density of $6 \mathrm{~mA} / \mathrm{cm}^{2}$ can achieve $94.2 \%$ of initial value after 100 cycles. 


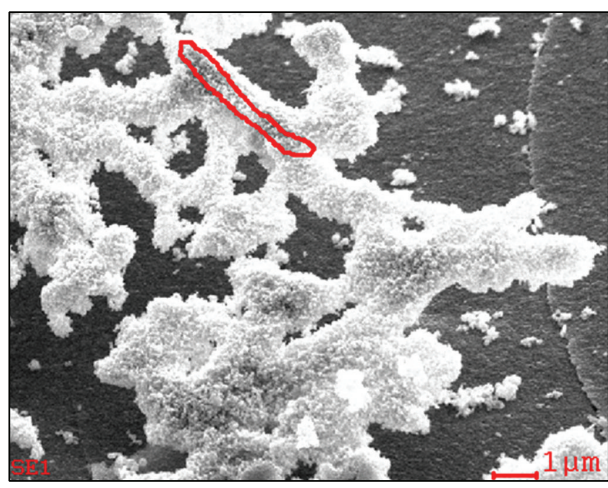

(a)

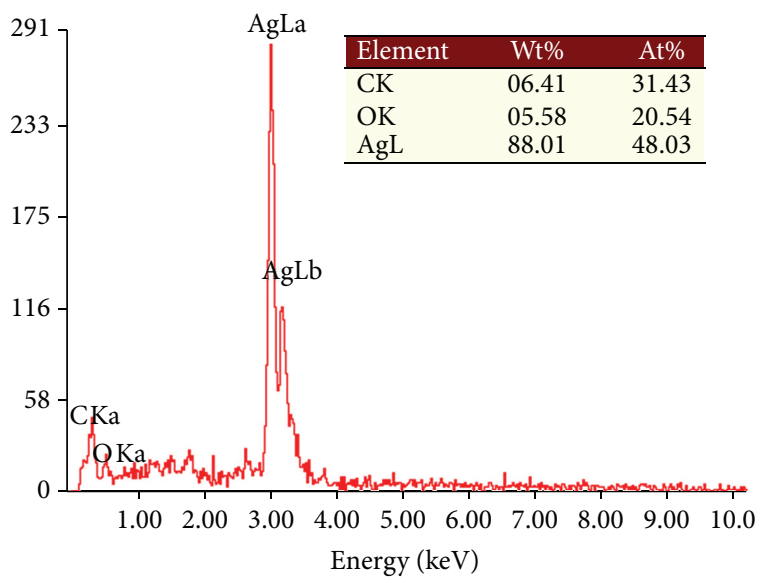

(b)

FIgure 5: (a) SEM image for I-film; (b) EDS for I-film.

TABLE 2: Specific capacitances of I-film at different current densities.

\begin{tabular}{lcccccc}
\hline $\begin{array}{l}\text { Current density } \\
\left(\mathrm{mA} / \mathrm{cm}^{2}\right)\end{array}$ & 0.5 & 1.0 & 1.5 & 2.0 & 3.0 & 6.0 \\
$\begin{array}{l}\text { Specific capacitance } \\
\left(\mathrm{mF} / \mathrm{cm}^{2}\right)\end{array}$ & 42.2 & 42.29 & 42.24 & 42.08 & 41.76 & 27 \\
\hline
\end{tabular}

As a result, the I-film electrode has a good stability during continuous cycles.

\section{Conclusions}

G-film and I-film have been fabricated by coating silver nanowires on glass and ITO, respectively. The transmittance of G-film increased with the decrease of the thickness of G-film, and the conductivity can be improved by increasing sintering temperature attributed to the remove of PVP and weld of junctions of silver nanowires. Results showed that G-film had higher ratio of transmittance to Rs than that of carbon nanotube and graphene, which is a promising replacement of ITO applied in optoelectronic areas. In addition, the CV curves of I-film under different scanning rates had obvious redox peaks indicating its good performance of electrochemical pseudocapacitance and good reversibility during charge/discharge process. Through galvanostatic charge/discharge experiments, it can be seen that

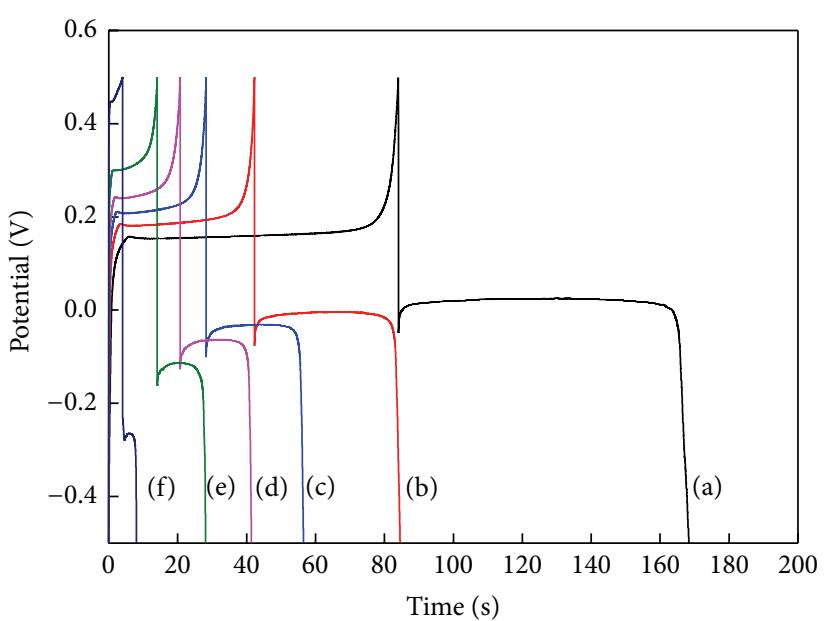
(a) $0.5 \mathrm{~mA} / \mathrm{cm}^{2}$
(b) $1.0 \mathrm{~mA} / \mathrm{cm}^{2}$
(d) $2.0 \mathrm{~mA} / \mathrm{cm}^{2}$
(c) $1.5 \mathrm{~mA} / \mathrm{cm}^{2}$
(e) $3.0 \mathrm{~mA} / \mathrm{cm}^{2}$
(f) $6.0 \mathrm{~mA} / \mathrm{cm}^{2}$

FIgURE 6: Galvanostatic charge/discharge curves of I-film under different current densities. (a) $0.5 \mathrm{~mA} / \mathrm{cm}^{2}$; (b) $1 \mathrm{~mA} / \mathrm{cm}^{2}$; (c) $1.5 \mathrm{~mA} / \mathrm{cm}^{2}$; (d) $2 \mathrm{~mA} / \mathrm{cm}^{2}$; (e) $3 \mathrm{~mA} / \mathrm{cm}^{2}$; (f) $6 \mathrm{~mA} / \mathrm{cm}^{2}$.

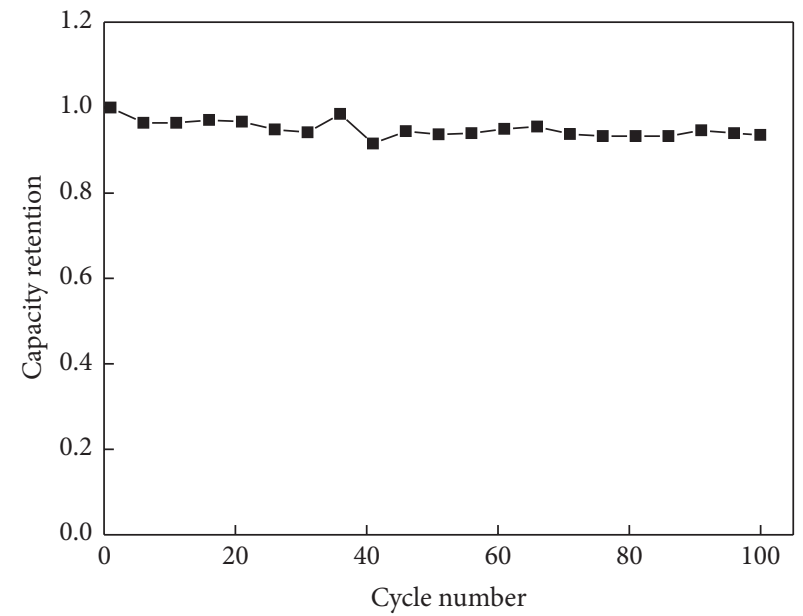

FIGURE 7: Capacity retention of I-film with respect to cycle numbers at a current density of $6 \mathrm{~mA} / \mathrm{cm}^{2}$.

the specific capacitance of I-film depends on the current density, and I-film exhibits high electrochemical stability. At low current density, the decay of specific capacitance can be ignored while, at high current density, the specific capacitance decayed dramatically because of short time for the diffusion of ions. Therefore, silver nanowires have great potential applications in optoelectronic devices.

\section{Conflict of Interests}

The authors declare that there is no conflict of interests regarding the publication of this paper.

\section{Acknowledgments}

This work is supported by NSFC under Grant no. 61307066, Doctoral Fund of Ministry of Education of China under 
Grants nos. 20110092110016 and 20130092120024, Natural Science Foundation of Jiangsu Province under Grant no. BK20130630, the National Basic Research Program of China (973 Program) under Grant no. 2011CB302004, and the Foundation of Key Laboratory of Micro-Inertial Instrument and Advanced Navigation Technology, Ministry of Education, China, under Grant no. 201204.

\section{References}

[1] C. Shi, M. Cheng, Z. Qu, and X. Bao, "Investigation on the catalytic roles of silver species in the selective catalytic reduction of NOx with methane," Applied Catalysis B: Environmental, vol. 51, no. 3, pp. 171-181, 2004.

[2] X. Y. Zhang, T. Zhang, S. Q. Zhu et al., "Fabrication and spectroscopic investigation of branched silver nanowires and nanomeshworks," Nanoscale Research Letters, vol. 7, article 596, 2012.

[3] M. N. Lin, S. Q. Zhu, X. Y. Zhang, T. Zhang, and D. Su, "Islandshaped gold nanoparticle film with controlable optical properties for surface enhancedRamanscattering," NRL Advances. In press.

[4] C. N. Lok, C. M. Ho, R. Chen et al., "Proteomic analysis of the mode of antibacterial action of silver nanoparticles," Journal of Proteome Research, vol. 5, no. 4, pp. 916-924, 2006.

[5] Y. H. Yoon, J. W. Song, D. Kim et al., "Transparent film heater using single-walled carbon nanotubes," Advanced Materials, vol. 19, no. 23, pp. 4284-4287, 2007.

[6] D. Kim, H. C. Lee, J. Y. Woo, and C. S. Han, "Thermal behavior of transparent film heaters made of single-walled carbon nanotubes," Journal of Physical Chemistry C, vol. 114, no. 13, pp. 5817-5821, 2010.

[7] L. Hu, D. S. Hecht, and G. Gruner, "Percolation in transparent and conducting carbon nanotube networks," Nano Letters, vol. 4, no. 12, pp. 2513-2517, 2004.

[8] B. Dan, G. C. Irvin, and M. Pasquali, "Continuous and scalable fabrication of transparent conducting carbon nanotube films," ACS Nano, vol. 3, no. 4, pp. 835-843, 2009.

[9] G. Eda, G. Fanchini, and M. Chhowalla, "Large-area ultrathin films of reduced graphene oxide as a transparent and flexible electronic material," Nature Nanotechnology, vol. 3, no. 5, pp. 270-274, 2008.

[10] Z. Wu, Z. Chen, X. Du et al., "Transparent, conductive carbon nanotube films," Science, vol. 305, no. 5688, pp. 1273-1276, 2004.

[11] X. Wang, L. Zhi, and K. Müllen, "Transparent, conductive graphene electrodes for dye-sensitized solar cells," Nano Letters, vol. 8, no. 1, pp. 323-327, 2008.

[12] H. D. Tran, D. Li, and R. B. Kaner, "One-dimensional conducting polymer nanostructures: bulk synthesis and applications," Advanced Materials, vol. 21, no. 14-15, pp. 1487-1499, 2009.

[13] X. Lu, W. Zhang, C. Wang, T. C. Wen, and Y. Wei, "Onedimensional conducting polymer nanocomposites: synthesis, properties and applications," Progress in Polymer Science, vol. 36, no. 5, pp. 671-712, 2011.

[14] Z. Yin and Q. Zheng, "Controlled synthesis and energy applications of one-dimensional conducting polymer nanostructures: an overview," Advanced Energy Materials, vol. 2, no. 2, pp. 179218, 2012.

[15] D. S. Leem, A. Edwards, M. Faist, J. Nelson, D. D. Bradley, and J. C. de Mello, "Efficient organic solar cells with solutionprocessed silver nanowire electrodes," Advanced Materials, vol. 23, no. 38, pp. 4371-4375, 2011.
[16] C. H. Liu and X. Yu, "Silver nanowire-based transparent, flexible, and conductive thin film," Nanoscale Research Letters, vol. 6, no. 1, article 75, 2011.

[17] D. Y. Choi, H. W. Kang, H. J. Sung, and S. S. Kim, "Annealingfree, flexible silver nanowire-polymer composite electrodes via a continuous two-step spray-coating method," Nanoscale, vol. 5, no. 3, pp. 977-983, 2013.

[18] S. M. Bergin, Y. H. Chen, A. R. Rathmell, P. Charbonneau, Z. Y. $\mathrm{Li}$, and B. J. Wiley, "The effect of nanowire length and diameter on the properties of transparent, conducting nanowire films," Nanoscale, vol. 4, no. 6, pp. 1996-2004, 2012.

[19] L. B. Hu, H. S. Kim, J. Y. Lee, P. Peumans, and Y. Cui, "Scalable coating and properties of transparent, flexible, silver nanowire electrodes," ACS Nano, vol. 4, no. 5, pp. 2955-2963, 2010.

[20] S. Zhu, Y. Gao, B. Hu et al., "Transferable self-welding silver nanowire network as high performance transparent flexible electrode," Nanotechnology, vol. 24, no. 33, Article ID 335202, 2013.

[21] K. K. Uprety, L. E. Ocola, and O. Auciello, "Growth and characterization of transparent $\mathrm{Pb}(\mathrm{Zi}, \mathrm{Ti}) \mathrm{O}_{3}$ capacitor on glass substrate," Journal of Applied Physics, vol. 102, no. 8, Article ID 084107, 2007.

[22] C. J. Xian and S. G. Yoon, "Transparent capacitor for the storage of electric power produced by transparent solar cells," Journal of the Electrochemical Society, vol. 156, no. 11, pp. G180-G183, 2009.

[23] L. Hu, J. W. Choi, Y. Yang et al., "Highly conductive paper for energy-storage devices," Proceedings of the National Academy of Sciences of the United States of America, vol. 106, no. 51, pp. 21490-21494, 2009.

[24] S. Sorel, U. Khan, and J. N. Coleman, "Flexible, transparent dielectric capacitors with nanostructured electrodes," Applied Physics Letters, vol. 101, no. 10, Article ID 103106, 2012.

[25] J. Pan, Y. Sun, Z. Wang, P. Wan, X. Liu, and M. Fan, "Nano silver oxide $(\mathrm{AgO})$ as a super high charge/discharge rate cathode material for rechargeable alkaline batteries," Journal of Materials Chemistry, vol. 17, no. 45, pp. 4820-4825, 2007.

[26] Z. A. Hu, Y. X. Wang, Y. L. Xie, Y. Y. Yang, Z. Y. Zhang, and H. Y. $\mathrm{Wu}$, "Ag nanowires and its application as electrode materials in electrochemical capacitor," Journal of Applied Electrochemistry, vol. 40, no. 2, pp. 341-344, 2010.

[27] Y. J. Song, M. L. Wang, X. Y. Zhang, J. Y. Wu, and T. Zhang, "Investigation on the role of the molecular weight of polyvinyl pyrrolidone in the shape control of high-yield silver nanospheres and nanowires," Nanoscale Research Letters, vol. 9, no. 1, article 27, 2014.

[28] K. C. Pradel, K. Sohn, and J. Huang, "Cross-flow purification of nanowires," Angewandte Chemie, vol. 50, no. 15, pp. 3412-3416, 2011.

[29] X. Tang, M. Tsuji, P. Jiang, M. Nishio, S. M. Jang, and S. H. Yoon, "Rapid and high-yield synthesis of silver nanowires using air-assisted polyol method with chloride ions," Colloids and Surfaces A: Physicochemical and Engineering Aspects, vol. 338, no. 1-3, pp. 33-39, 2009.

[30] Y. G. Sun, Y. D. Yin, B. T. Mayers, T. Herricks, and Y. N. $\mathrm{Xia}$, "Uniform silver nanowires synthesis by reducing $\mathrm{AgNO}_{3}$ with ethylene glycol in the presence of seeds and poly(vinyl pyrrolidone)," Chemistry of Materials, vol. 14, no. 11, pp. 47364745, 2002.

[31] J. Y. Lee, S. T. Connor, Y. Cui, and P. Peumans, "Solutionprocessed metal nanowire mesh transparent electrodes," Nano Letters, vol. 8, no. 2, pp. 689-692, 2008. 
[32] H. Z. Geng, K. K. Kim, K. P. So, Y. S. Lee, Y. Chang, and Y. H. Lee, "Effect of acid treatment on carbon nanotube-based flexible transparent conducting films," Journal of the American Chemical Society, vol. 129, no. 25, pp. 7758-7759, 2007.

[33] P. N. Nirmalraj, P. E. Lyons, S. De, J. N. Coleman, and J. J. Boland, "Electrical connectivity in single-walled carbon nanotube networks," Nano Letters, vol. 9, no. 11, pp. 3890-3895, 2009.

[34] S. De and J. N. Coleman, "Are there fundamental limitations on the sheet resistance and transmittance of thin graphene films?" ACS Nano, vol. 4, no. 5, pp. 2713-2720, 2010.

[35] M. Takeji, Y. Oaki, and H. Imai, "Electrically guided microweb formation with Ag nanofibers under UV irradiation and its application to electrochemical and plasmonic devices," Journal of Physical Chemistry C, vol. 116, no. 10, pp. 6103-6107, 2012.

[36] H. Adelkhani, K. Didehban, and M. Hayasi, "Performance evaluation of polyacrylamide/silver composite as electrode material in electrochemical capacitor," Current Applied Physics, vol. 13, no. 3, pp. 522-525, 2013.

[37] Y. Xie and X. Fang, "Electrochemical flexible supercapacitor based on manganese dioxide-titanium nitride nanotube hybrid," Electrochimica Acta, vol. 120, pp. 273-283, 2014.

[38] R. Liu and S. B. Lee, " $\mathrm{MnO}_{2} /$ poly(3,4-ethylenedioxythiophene) coaxial nanowires by one-step coelectrodeposition for electrochemical energy storage," Journal of the American Chemical Society, vol. 130, no. 10, pp. 2942-2943, 2008. 

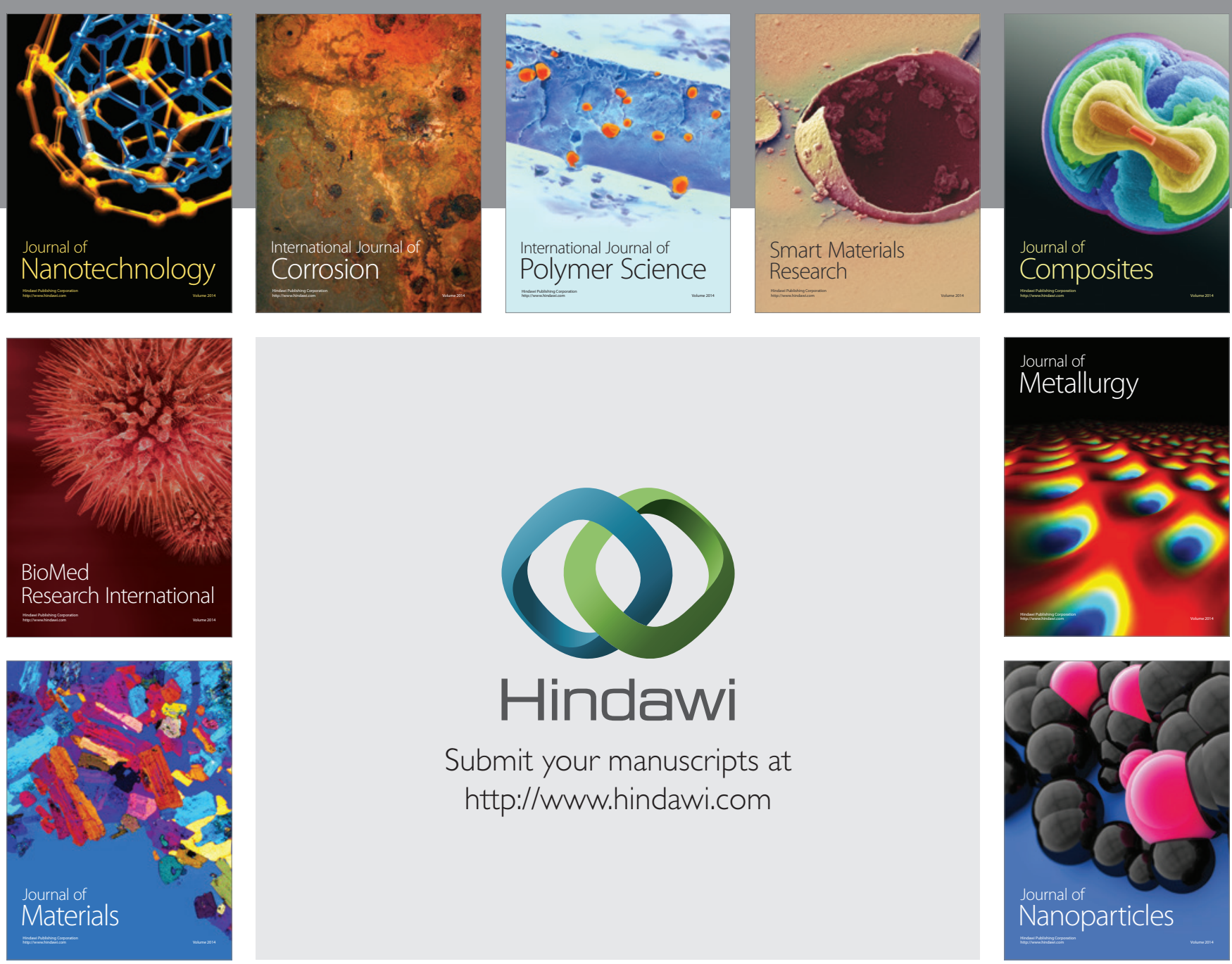

Submit your manuscripts at http://www.hindawi.com
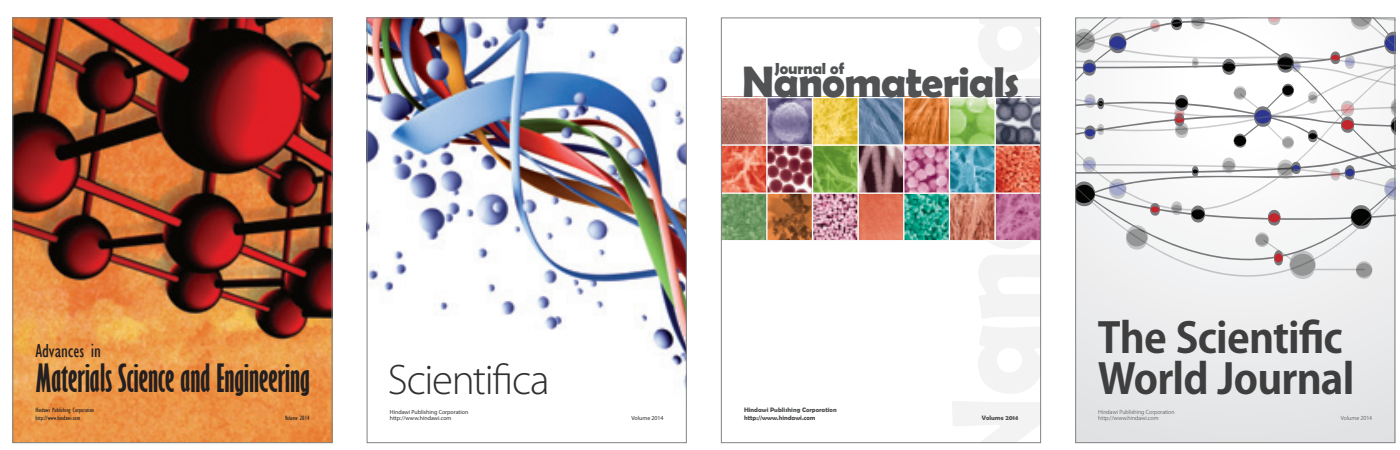

\section{The Scientific World Journal}
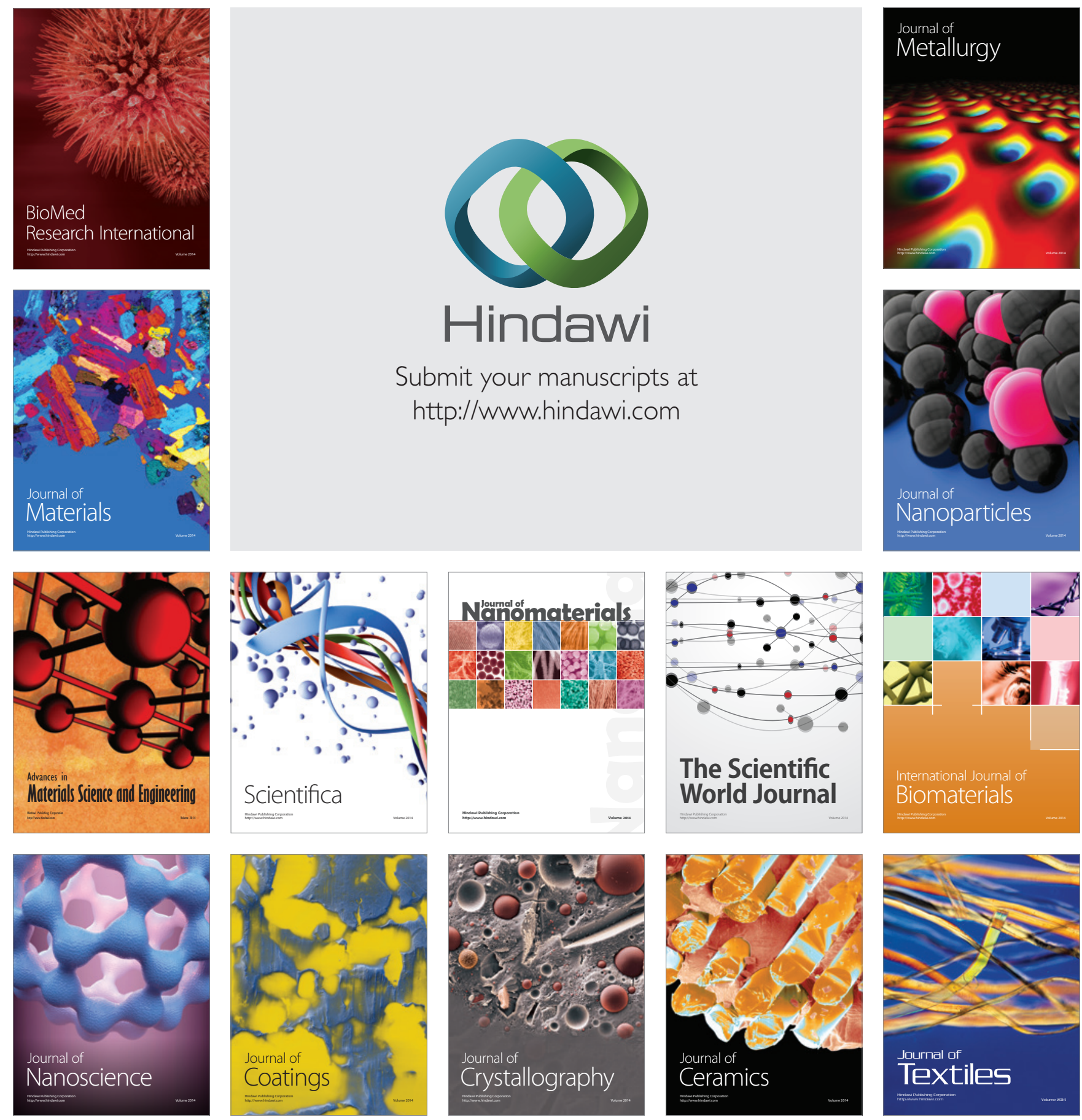